\title{
eCOti
DiAno
}

Revista Mídia e Cotidiano

Artigo Seção Temática

Volume 13, Número 3, dezembro de 2019

Submetido em: 30/09/2019

Aprovado em: 27/11/2019

\section{Crise epistemológica e teorias da conspiração: o discurso anti-ciência do canal "professor terra plana"}

\section{Epistemological crisis and conspiracy theories: the anti-science speech of "professor terra plana" channel}

\author{
Afonso de ALBUQUERQUE ${ }^{1}$ \\ Rodrigo QUINAN ${ }^{2}$
}

\section{Resumo}

Este artigo pretende analisar a construção de autoridade científica em vídeos do YouTube de teoristas da conspiração que defendem que a Terra é plana. Analisaremos aqui como a cultura de teorias da conspiração é diretamente ligada ao enfraquecimento das instituições da modernidade. Debateremos o papel das políticas do YouTube como distribuidor deste conteúdo e usaremos o canal brasileiro Professor Terra Plana para exemplificar estas práticas.

Palavras-chave: Conspiração; YouTube; Pseudociência; Crise da Epistemologia.

\begin{abstract}
This paper seeks to analyze the construction of scientific authority in YouTube videos made by flat Earth conspiracy theorists. We analyze here how this conspiracy culture is directly connected to the weakening of modern institutions. We discuss the role of YouTube as a distributor of this content and use the brazilian channel "Professor Terra Plana" to exemplify these practices.
\end{abstract}

Keywords: Conspiracy; YouTube; Pseudoscience; Epistemological Crisis.

\section{Introdução}

A Terra é plana. O Sol está a apenas 700 milhas acima da Terra. Ele tem o mesmo tamanho da Lua. O espaço sideral é uma farsa arquitetada pela NASA. A gravidade não existe. Satélites são uma fabricação fictícia - o mundo está na verdade

\footnotetext{
${ }^{1}$ Professor Titular do curso de Estudos de Mídia e do Programa de Pós-Graduação da Universidade Federal Fluminense.E-mail: afonsoal@uol.com.br

${ }^{2}$ Mestrando em Comunicação do Programa de Pós-Graduação da Universidade Federal Fluminense. Email: rodrigoquinan@id.uff.br
} 


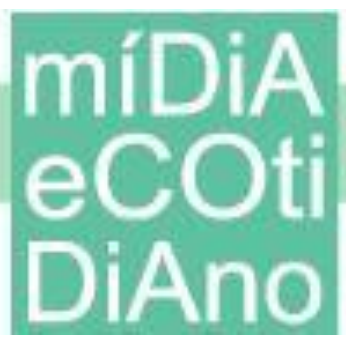

interligado apenas por torres e cabos. Tais argumentos seriam tratados como irracionais, sendo categorizados no campo da pseudociência por cientistas. Eles também provavelmente não seriam explorados ou sequer mencionados em documentários, noticiários ou qualquer espaço pertencente à mídia tradicional. Ainda assim eles não só existem, mas encontram cada vez mais reverberação em um mundo onde novas tecnologias reconfiguram o espaço e a repercussão recebida por descrentes à ciência. Movimentos negacionistas, geralmente influenciados por literalismo bíblico, existem há muito tempo - a International Flat Earth Society foi fundada em 1956 (GARWOOD, 2007) - mas recentemente ganharam novo fôlego, aproveitando as oportunidades tecnológicas propiciadas pelas mídias sociais, tais como de fóruns especializados ${ }^{3}$, blogs e, especialmente, o YouTube, povoado com canais que levam conteúdo terraplanista a grandes audiências de uma forma jamais possível na mídia tradicional.

Para além do seu exotismo, a crescente visibilidade adquirida por movimentos negacionistas como o terraplanismo - e outros, como os movimentos antivacina e de contestação ao aquecimento global - dão conta de um desafio inédito que se apresenta à sociedade contemporânea, de modo geral e, de modo especial, ao papel que cabe à universidade desempenhar nela. Ela se articula com uma crise da democracia, de escala global e, de modo mais abrangente, a uma crise epistemológica, que se traduz na perda de confiança em instituições fundamentais da sociedade, dentre as quais a própria universidade. Esse ponto tem sido ilustrado, de maneira exemplar, pelo atual governo do presidente Jair Bolsonaro e, em particular, pela influência que nele exerce o autoproclamado filósofo Olavo de Carvalho, responsável pela nomeação de dois ministros: Abraham Weintraub, da Educação e Ernesto Araújo das Relações Exteriores ${ }^{4}$. Ambos têm se notabilizado pelo desdém manifestado em relação à educação formal: enquanto Weintraub promoveu um massivo corte de verbas que compromete o

\footnotetext{
${ }^{3}$ A Flat Earth Society é digitalizada em 2004, e hoje conta com fóruns, redes sociais e uma wiki. Disponível em: <https://theflatearthsociety.org/home/>. Acesso em: 28 set. 2019.

${ }^{4}$ Sobre a importância do papel que Olavo de Carvalho como ponto de referência para a organização da militância bolsonarista ver Santos Junior (2019).
} 
funcionamento da educação superior no Brasil ${ }^{5}$, Araújo afirmou que o aquecimento global é, de fato, uma conspiração comunista ${ }^{6}$ para facilitar a competitividade da China frente aos países ocidentais. Marcio Labre, deputado do PSL-RJ, chegou a ponto de declarar: "E se a terra for plana, qual o problema?"7, saindo em defesa aos pontos de vista de Olavo.

Dada a magnitude da influência que esses movimentos exercem no mundo atual, é de se destacar a pouca atenção que eles têm recebido por parte da literatura acadêmica. O novo cenário traz desafios inéditos para a divulgação científica (e, também, no campo da política e do jornalismo), já que a base dos consensos tácitos nos quais essas atividades se sustentam são, hoje, postos à prova. Esse artigo se propõe a fazer uma contribuição a esse respeito, tendo em vista uma análise preliminar de um exemplar brasileiro da cultura conspiratória terraplanista: o canal Professor Terraplana no YouTube. Para tal, ele desenvolve seu argumento em quatro partes. A primeira considera os movimentos negacionistas em seu contexto histórico, tendo em vista a emergência de uma cultura da conspiração na segunda metade do século XX. A segunda parte situa a recente expansão dos movimentos negacionistas no contexto de uma crise epistemológica, que abala consensos sociais e, portanto, cria um terreno fértil para eles. A terceira explora as características do YouTube, a plataforma na qual se situa o canal e, finalmente, a última se vale do canal do YouTube Professor Terra Plana como ponto de partida para discutir aspectos da cultura terraplanista.

\section{Crise da verdade e cultura de teorias da conspiração}

Tornou-se corrente a percepção de que experimentamos atualmente uma crise epistemológica de grandes dimensões. O tema tem sido considerado sob diferentes pontos de vista. Duas chaves de análise particularmente populares remetem aos conceitos de "pós-verdade" e "fake news". "Em 2016 o Dicionário Oxford nomeou 'pós verdade' a

\footnotetext{
5 Ministro da educação anunciou em 2019 massivo corte de verbas. Disponível em: <https://bit.ly/2s0WixF>. Acesso em: 12 nov. 2019.

${ }^{6}$ Araújo defendeu que aquecimento global é uma "trama marxista" <https://glo.bo/2rfx3I6>. Acesso em: 12 nov. 2019.

7 Deputado do partido de Bolsonaro saiu em defesa do terraplanismo de Olavo de Carvalho <https://bit.ly/2Lmk5io>. Acesso em: 12 nov. 2019.
} 


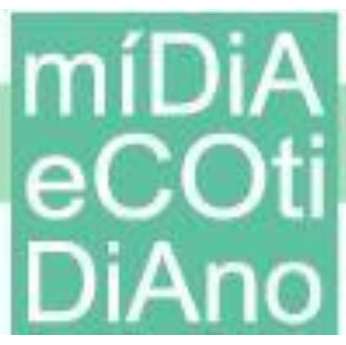

palavra do ano": com uma frequência extraordinária, textos que exploram o tema têm nessa informação o seu ponto de partida. Em linhas gerais, o termo dá conta de uma crise da comunicação pública, associada ao advento de um aparato mediático tão vasto e complexo, que resulta no advento de uma hiper-realidade, "mais real do que o real" (LILLEKER, 2018). O debate sobre fake news se tornou ainda mais popular, tanto no meio acadêmico quanto no debate público de modo geral. De maneira geral, o termo tem sido utilizado para dar conta de uma diversidade de fenômenos. Por exemplo, ele se refere tanto a conteúdo malicioso que se apropria de um formato noticioso para desinformar o público, como a conteúdos que se apropriam do formato para fins humorísticos (TANDOC, LIM \& LING, 2018), como é o caso do Sensacionalista ${ }^{8}$ : "um jornal isento de verdade". Em outro recorte, ele diz respeito tanto a um fenômeno concreto quanto a um discurso que classifica determinados conteúdos como fake news a fim de desautorizálos. Habgood-Coote (2019) denunciou o caráter epistemologicamente vago do conceito e recomendou simplesmente que seja abandonado. Contudo, como regra geral, os pesquisadores tomam o conceito como um dado, frequentemente associando iniciativas massivas de promoção de fake news a potências estrangeiras, particularmente a Rússia (BOYD-BARRETT, 2018). Ambos os conceitos apontam para uma crise que se originaria na influência de agentes externos às instituições tradicionais.

Alternativamente, nosso texto propõe que a atribuição da crise exclusivamente a agentes externos empobrece a análise. Se esses agentes podem obter alguma credibilidade, isso acontece porque a autoridade das instituições que tradicionalmente ocupavam o centro do tabuleiro tem sido crescentemente desafiada (DAHLGREN, 2018). É somente na medida em que isso acontece que podemos entender o contexto no qual as teorias da conspiração saíram da dinâmica particularista que as caracterizava e se tornou um elemento capaz de contestar, com um sucesso crescente, as interpretações que definiam o senso comum até muito pouco tempo.

Keeley (1999, p.4) define teorias da conspiração, como "uma explicação proposta para algum evento histórico (ou eventos) em termos de agência de casualidade

\footnotetext{
8 O noticiário satírico foi fundado em 2009. Disponível em: <https://www.sensacionalista.com.br/>. Acesso em: 30 set. 2019.
} 


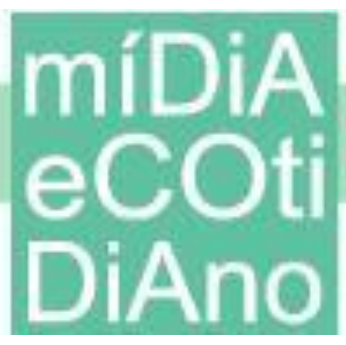

significativa de um grupo relativamente pequeno de pessoas - ou conspiradores - agindo em segredo". O termo é adotado para se referir a tentativas de explicação alternativas àquelas veiculadas oficialmente pela imprensa, ciência ou governos. (SILVA, 2010)

Enquanto o argumento de que a Terra é plana originalmente não era uma teoria da conspiração, mas aceito como um dado por civilizações antigas (GARWOOD, 2007) sua alegação na modernidade é, na medida em que contesta evidências científicas fartamente documentadas sobre o formato esférico da Terra. Teorias da conspiração também não são um fenômeno recente - por exemplo, a teoria de que os Iluminatti estariam por detrás de todos os conflitos armados remonta aos tempos da Revolução Francesa (AZARIAS, 2015), mas neste artigo focamos nossa atenção em um conjunto de teorias que emergiu ao longo do século XX.

As décadas de 1960 e 1970 são importantes nesse sentido na medida em que uma série de eventos particulares alimentou uma desconfiança do público americano em relação às suas próprias instituições políticas e abalou o seu patriotismo. Três acontecimentos em especial são pesadamente televisados e influenciam em definitivo esta percepção institucional: o assassinato do presidente John F. Kennedy gera na cultura popular uma série de interpretações alternativas ao evento e pode ser considerado como marco principal da cultura de teorias da conspiração na modernidade; a Guerra do Vietnam gerou forte oposição da população americana, contestando as razões para seu governo entrar em guerra; e enfim o escândalo do Watergate, que agressivamente mudou a percepção estadunidense sobre suas instituições públicas.

A crise que resultou no impeachment do presidente Richard Nixon rompeu com o otimismo patriota pós-guerra dos Estados Unidos ao mostrar em grande escala que seu governo poderia ser corrupto nos níveis burocráticos mais altos. A pesada cobertura da imprensa significava não apenas que uma parcela gigante da população teve acesso a detalhes do escândalo, mas que os veículos de comunicação perceberam o quão lucrativa é esta cobertura (SOUKUP, 2002), resultando em um interesse midiático ainda maior em explorar escândalos políticos nas próximas décadas, especialmente a partir da década de 1990.

A década de 1990 dá início a um período marcado por hegemonia política e econômica dos Estados Unidos, após o fim da União Soviética. O fim da Guerra Fria 
representa o fim da principal estratégia de manutenção ao nacionalismo americano: o uso da paranoia através da figura do soviético como o "outro", um bode expiatório considerado "inimigo maior" e utilizado como justificativa para diversas ações governamentais. Este é o período identificado por acadêmicos como inicial de uma mudança de direção da paranoia ocidental: enquanto desde os anos 50 teorias da conspiração tinham comunistas, judeus e islâmicos como alvos - o "outro" para o ocidental - as próprias instituições da modernidade passam a ser o alvo de suspeita neste fim de século no ocidente (AUPERS, 2012). Descrevendo a transição de uma "paranoia segura" para uma "paranoia insegura", Knight (2000, p. 4) aponta que o “conspiracionismo popular sofreu uma mutação de uma obsessão com um inimigo fixado para uma suspeição generalizada sobre forças conspiradoras".

Esta proliferação do pensamento conspiracionista no Ocidente é exemplificada pela fascinação da cultura popular por filmes e seriados mainstreans como “JFK” (1991), “Arquivo X” (1993), “Independence Day” (1996), "Matrix” (1999) e "24 Horas" (2001), abordando conspirações e a busca pela verdade nas suas histórias. Ironicamente, acadêmicos identificam o ceticismo e o espírito questionador como elementos típicos do indivíduo da própria modernidade (NICOLAS, 2016), com Giddens (1992, p.21) definindo a própria ciência como "dependente não apenas do princípio da acumulação de provas, mas da metodologia da dúvida", mesma lógica por trás das teorias da conspiração, que trabalham em cima da desconfiança não apenas em instituições, mas na ideia de que a realidade é o que parece ser.

Esta negação do real é parte da lógica fundamental das teorias da conspiração. A ideia é levada ao extremo em teorias como, por exemplo, as que envolvem o massacre escolar de Sandy Hook, em 2012: teóricos da conspiração afirmaram que o massacre nunca aconteceu, mas foi uma fabricação de uma imprensa conspiradora. Os próprios pais das crianças, em luto, seriam atores, pagos por forças ocultas. Embora em certa medida essa abordagem possa ser interpretada como uma resposta de negação, para lidar com eventos traumáticos, encontrando conforto em ideias alternativas onde vidas não foram perdidas (WOOD, 2013), ela dá conta de um afastamento dos indivíduos de suas próprias instituições. Isso ocorre, em parte, porque, em um contexto de crescente complexidade social eles desconhecem a lógica funcional por detrás de fenômenos como os governos, 


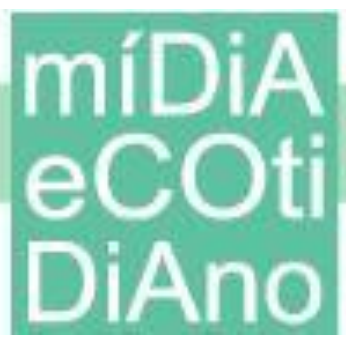

a economia, a medicina, os meios de comunicação, dentre outros (GIDDENS, 1992). Mannheim (1946 [1935], p.59) compara as instituições da modernidade para o homem moderno com a natureza para o homem pré-moderno, ambas "forças impossíveis de entender" e causadoras da ansiedade dos indivíduos de suas épocas, enquanto Baudrillard (2000, p.12) identifica um "pânico de agência", onde a paranoia moderna é direcionada a quão desconhecidas são as forças que atuam na vida dos seus indivíduos: “[...] ]eu sou eu mesmo de verdade? Ou eu sofri lavagem cerebral, fui domesticado e programado pelo sistema?”.

Frustrando cientistas sociais do século XIX e XX, que previam um monopólio da verdade do pensamento científico após a queda da autoridade religiosa, a ciência, suas produções e soluções se tornam cada vez mais encaradas com ceticismo pelo indivíduo ocidental (AUPERS, 2012), com essa deslegitimação cada vez mais cotidiana (GIDDENS, 1992). Não apenas as fundações epistemológicas, criticadas desde o século XVI, são questionadas, mas a versão da ciência apresentada pela mídia de massa também contribui para sua deslegitimação. Enquanto ela disponibiliza o debate para um público maior e mais afastado de instituições acadêmicas através de jornais, revistas, programas de televisão e rádio, sua versão sensacionalista e contraditória diminui sua credibilidade (AUPERS, 2012); a falha da ciência em tratar de questões como a desigualdade social também contribui para o descrédito (OLIVEIRA, 2019).

Numa sociedade de risco, onde os indivíduos temem pelo que pode acontecer a seguir (pobreza, desordem, catástrofes, terrorismo) (BECK, 1992), e eles próprios se tornam céticos em relação às instituições que controlam suas vidas, uma alternativa que se apresenta é buscar a verdade em si mesmos. Lasch se referiu a esse movimento como cultura de narcisismo (LASCH, 1979), na qual os indivíduos buscam o conhecimento de si mesmos através da popularização da terapia (conhecer a si mesmo), espiritualismo ou autoajuda (melhorar a si mesmo) e, recentemente, mídias sociais (expressar a si mesmo). O interesse no pessoal faz com que jornalismo, literatura, televisão e internet favoreçam cada vez mais conteúdo autobiográfico ou confessional (VAN ZOONEN, 2012), levando Dovey (2000, p.1) a usar o termo first person media para definir estas práticas midiáticas cada vez mais interessadas no privado e no pessoal, como talk shows e reality shows. 
Com experiências pessoais (como relatos próprios, ou de algum parente ou alguém próximo) no topo da hierarquia de credibilidade de informação para sujeitos da modernidade e a suspeitas em relação à mídia tradicional, a opinião pessoal não-mediada passa a ter um peso político importante. Há exemplos dos dois lados do campo político: partidos populistas de extrema-direita da Europa, por exemplo, podem utilizar experiências pessoais para moldar o imaginário de um "eu" que considera, através de relatos emotivos pessoais, apenas brancos e cristãos de classe média, como o partido antiislã holandês que usa a frase "Eu, Eu, Eu, O resto pode morrer" (AARTS; VAN DER KOLK, 2006); enquanto grupos de esquerda, desde a segunda onda do feminismo, fortalecem relatos pessoais de mulheres, negros e LGBTs acima das instituições tradicionais, por considerarem o olhar delas comprometido, por serem compostas, em sua maioria, por homens brancos e heterossexuais (VAN ZOONEN, 2012).

A Internet é o caminho lógico para uma sociedade onde o olhar pessoal tem esse tipo de peso, com a aparente falta de mediação, sua possibilidade de participação e a acessibilidade de plataformas e ferramentas fazendo-a ser percebida como espaço mais democrático para se acessar a "verdade" (AUPERS, 2012). Neste espaço, o conhecimento deslegitimado pela ciência como inválido encontra nova ressonância graças à reconfiguração da relação entre consumidor e produtor de conteúdo. Analisaremos agora as políticas que permitem essa reconfiguração na maior nova mídia dedicada a conteúdo audiovisual, o YouTube.

\section{A permissividade da "plataforma" YouTube}

Fundado em 2005, o marco da história do site de compartilhamento de vídeos é outubro de 2006, quando é adquirido pelo Google ${ }^{9}$ e passa a fazer parte de um guardachuva de sites da empresa ao lado de produtos e serviços como Gmail, Google Maps, Google + e Google Chrome. A crescente popularidade do YouTube, que se estabelece em

\footnotetext{
9 Anúncio da compra do YouTube pelo Google em 2006, publicado no site da CNN. Disponível em: <https://money.cnn.com/2006/10/09/technology/googleyoutube_deal/>. Acesso em: 28 set. 2019.
} 
pouco tempo como o principal site dedicado a conteúdo audiovisual e um dos sites mais acessados de toda a Internet (em janeiro de 2019 está em $2^{\circ}$ no ranking da medidora de tráfego online Alexa ${ }^{10}$ ), leva o Google a adotar políticas específicas para lidar legalmente com a gigante quantidade de conteúdo que o site passa a receber.

Chegando a receber 400 horas de conteúdo por minuto ${ }^{11}$, o YouTube disponibiliza, em um mês, mais material audiovisual do que todas as três maiores operadoras da TV americana nos últimos 60 anos (VAN DJICK, 2013). É neste enorme catálogo, transferido a seus servidores globalmente, que começam os problemas legais do site, que, ao contrário da televisão, não tem uma grade controlada de 24 horas de programação. Contendo tanto conteúdo gerado por usuários quanto por empresas, o YouTube disponibiliza uma variedade de conteúdos como vídeos pessoais, trechos de programas de televisão, vídeos musicais, documentários, vlogs, trailers, transmissões ao vivo e vídeos educacionais. Inevitavelmente, parte deste conteúdo - especialmente a que replica conteúdo das "velhas mídias", contendo trechos de programas de TV ou uploads ilegais de músicas - contém infrações a conteúdos autorais, e não tardaria para o Google enfrentar problemas jurídicos, como um processo do conglomerado de mídia Viacom em $2007^{12}$.

Dono de canais de televisão como MTV, VH1, Nickelodeon e Comedy Central, o grupo pedia 1 bilhão de dólares de reparo pelos inúmeros vídeos de seu conteúdo transferidos sem autorização por usuários ao YouTube. A Viacom alegava que o site do Google era um "distribuidor" do conteúdo, uma vez que os vídeos estavam sob seus domínios e, graças às propagandas, eram lucrativos a ele. A briga jurídica se arrastou por anos, terminando em 2014 com vitória do Google após desistência da Viacom, em um período marcado pela aproximação do YouTube com os grandes grupos de mídia, oferecendo a eles ferramentas como o Content $\mathrm{ID}^{13}$, um algoritmo que rastreia conteúdo

10 Dados da companhia Alexa Internet sobre tráfego de dados no YouTube. Disponível em: <https://www.alexa.com/siteinfo/youtube.com>. Acesso em: 30 set. 2019.

${ }^{11}$ Números do portal Statista sobre a quantidade de horas disponibilizada no YouTube até Maio de 2019. Disponível em: 〈https://bit.ly/2rTQHJC〉. Acesso em: 25 set. 2019.

12 Reportagem de 2007 pela CBS News, detalhando a ação judicial do Viacom Inc. contra o YouTube. Disponível em: <https://cbsn.ws/389WfQH>. Acesso em: 30 set. 2019.

13 Página de suporte do Google explicando o funcionamento do Content ID. Disponível em: <https://support.google.com/youtube/answer/2797370?hl=pt-BR>. Acesso em: 30 set. 2019. 


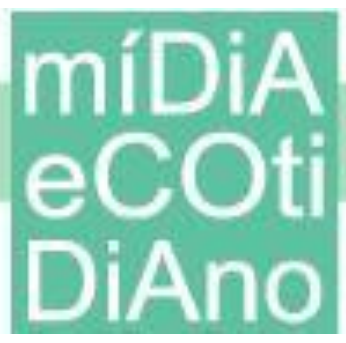

ilegal, e benefícios como o próprio uso do espaço para disponibilizar de forma oficial seu conteúdo com uma visibilidade superior ao do usuário comum, em um polêmico processo de mudanças ocorrido no site em 2011. Nele, o YouTube foi acusado de se afastar das suas origens como uma rede comunitária e colaborativa para trabalhar lado-a-lado com os grandes grupos de mídia aos quais fazia oposição poucos anos antes (VAN DJICK, 2013).

Antes da compra pelo Google, o YouTube era moderado por usuários comuns. Hoje, ele é censurado por algoritmos que detectam infrações a direitos autorais, conteúdo pornográfico ou excessivamente violento, por exemplo. Mesmo mais atenta ao conteúdo autoral, a regulamentação do YouTube é ajustada de acordo com sua conveniência comercial: seus algoritmos não só censuram conteúdo, mas controlam a popularidade de produtores de conteúdo com sugestões, rankings, reproduções automáticas (numa tentativa de replicar oflow televisivo), o que faz do site um ambiente controlado similar à televisão onde o distribuidor, em posse do conteúdo, colhendo dinheiro publicitário através dele, controla sua repercussão. Ainda assim, o YouTube estrategicamente limita sua associação a seu conteúdo, rejeitando exatamente o título de “distribuidor", levantado nas ações judiciais da Viacom, para se auto intitular como "plataforma" (GILLESPIE, 2010).

O termo é a parte central da estratégia do YouTube de minimizar seu papel como mediador. O Google o anuncia com a imagem de um serviço público facilitador, guardião da liberdade de expressão, que tem como trabalho meramente dar voz em iguais condições para qualquer um dos seus usuários, escondendo assim os algoritmos e as tecnologias que dão mais ou menos visibilidade para conteúdos de acordo com seus interesses comerciais. Da mesma forma, em muitos destes processos autorais o Google usou o status de "plataforma" para fugir de qualquer responsabilidade sobre o conteúdo não autorizado, tentando transferir esta responsabilidade para seus usuários (GILLESPIE, 2010).

Apesar de deletar conteúdo pornográfico ou violento, também restringindo, de forma polêmica ${ }^{14}$, boa parte do conteúdo identificado pelo site como "sensível" a um

\footnotetext{
${ }^{14}$ Matéria do portal TechCruch sobre mudanças de políticas no YouTube após bloqueio de conteúdo LGBT. Disponível em: <https://tcrn.ch/2Yk2KfC>. Acesso em: 26 set. 2019.
} 


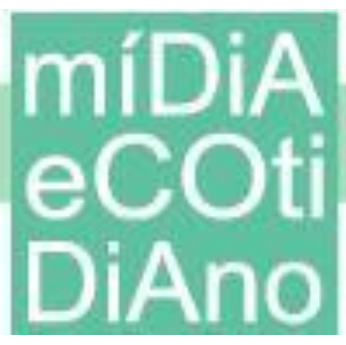

modo restrito, que requer o login do usuário, o YouTube enfrenta críticas dos seus anunciantes por falta de censura a conteúdo extremista. Enquanto o Facebook enfrenta críticas por fazer exatamente o contrário, cedendo à pressão de anunciantes e banindo, por exemplo, jornalistas palestinos ${ }^{15}$ e ativistas do movimento negro ${ }^{16}$, o YouTube é mais flexível, interferindo minimamente em seu conteúdo; por exemplo, sendo criticado por manter em seus servidores vídeos de negacionismo do holocausto ${ }^{17}$.

A relação de cada site com seus anunciantes pode explicar suas políticas diferentes com a censura: o Facebook lucra inicialmente com a interação entre usuários, enquanto o YouTube depende exclusivamente do tempo que cada usuário passa assistindo a seus vídeos. A negligência do Google em banir conteúdo que desagrada parte de seus anunciantes, parte da imprensa ocidental e parte dos usuários vem da noção de que todo tipo de audiência é importante para o sucesso comercial do site. Esta é uma noção herdada especialmente das lógicas da televisão paga a partir da década de 1990, onde em um mundo neoliberal com consumidores marcados por uma fragmentação identitária, o ambiente televisivo é também fragmentado em dezenas de diferentes canais dedicados a atender nichos cada vez mais específicos (MITTEL, 2015), de audiências de diferentes gêneros, idades, classes sociais, orientações sexuais, cores, religiões, etnias e visões políticas.

Parks (2004, p. 135, tradução nossa) usa o termo "flexible microcasting” para definir "um conjunto de práticas industriais e tecnológicas que trabalham para isolar os gostos culturais dos espectadores/consumidores para refinar e direcionar o marketing televisivo - em outras palavras, o processo de levar audiências específicas para anunciantes específicos". Enquanto o trecho define uma prática televisiva, ele se adequa perfeitamente ao YouTube: seus vídeos são divididos em dezenas de categorias, direcionadas para anunciantes específicos, e seu catálogo global significa uma ampla

15 Coluna do jornal The Guardian analisando a política de censura do YouTube. Disponível em: <https://bit.ly/2Pjo68u>. Acesso em: 28 set. 2019.

16 Relato do The NY Times sobre a remoção de conteúdo do movimento "Black Lives Matter" no Facebook. Disponível em: <https://nyti.ms/2YgBhvf>. Acesso em: 27 set. 2019.

17 Matéria no Expressen sobre a circulação de conteúdo anti-semita, neo-nazista e negacionista no YouTube. Disponível em: 〈https://bit.ly/33JG61a〉. Acesso em: 30 set. 2019. 


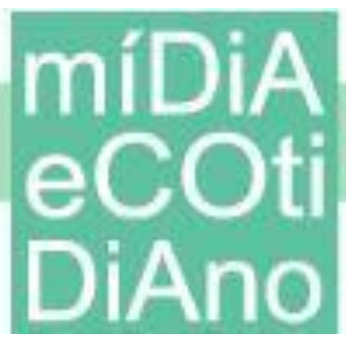

cobertura de diversos nichos e identidades de consumo. A diferença para a televisão é a forma como o YouTube se afasta da noção de produtor de conteúdo.

Apesar da diversificação da audiência televisiva na TV a cabo trazer novos canais produtores de conteúdo que, longe das regulamentações dos grandes canais, têm conteúdo mais diversificado e permissivo (como por exemplo a tradicional nudez e violência no conteúdo da HBO; ou uma animação ofensiva como South Park no Comedy Central), mesmo os menores e mais específicos canais de televisão tomam responsabilidade pelo seu conteúdo e têm alguma credibilidade a zelar com sua audiência. Os já mencionados conteúdos a favor de grupos extremistas, negação do holocausto, teorias da conspiração e pseudociência não teriam na TV a repercussão ou sequer a liberdade de estar no ar que tiveram no YouTube.

Apesar de a televisão ter sua história de exibição de pseudociência, como por exemplo a autópsia de um extraterrestre exibida na Fox em 1995, elas não veio sem repercussões negativas à imagem do veículo ${ }^{18}$, enquanto $\mathrm{o}$ YouTube tem $\mathrm{o}$ distanciamento ideal para seus produtores de conteúdo, sempre respondendo às críticas sobre manter conteúdo desinformativo, extremista ou inadequado com o argumento de que defende a "liberdade de expressão" (VAN DJICK, 2013).

Isso faz do site a plataforma ideal para a expressão dos indivíduos tratados na primeira parte do texto: a facilidade do upload no YouTube, a disponibilidade de tecnologia acessível para edição de vídeo e a permissividade de se manter no ar, se divulgar e repercutir dá espaço para o surgimento em massa de conteúdo de teorias da conspiração e pseudociência. Essa acessibilidade das ferramentas audiovisuais se adequa perfeitamente às práticas das teorias da conspiração: seus adeptos releem, renegociam e reescrevem a história; recriam narrativas sobre a verdade e produzem suas próprias evidências (AUPERS, 2012) - estas que podem ser buscadas em outros vídeos do próprio

\footnotetext{
${ }^{18}$ Reportagem de 1995 da revista Time sobre a famosa circulação de um vídeo contendo uma autópsia de um extraterrestre nos anos 90. Disponível em: <https://bit.ly/2Pfi5da>. Acesso em: 30 set. 2019.
} 


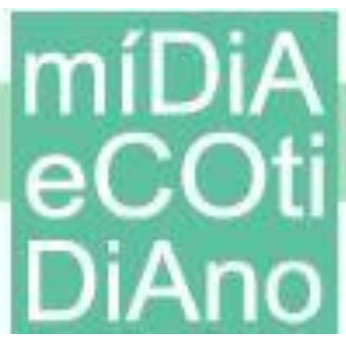

YouTube, como por exemplo buscando pistas de detalhes despercebidos em vídeos de atentados terroristas.

O YouTube tem enfrentado timidamente o problema da desinformação, tendo anunciado recentemente que o algoritmo será programado para recomendar menos (mas não excluir) vídeos de teorias da conspiração ${ }^{19}$. O famoso teórico da conspiração Alex Jones teve seu canal de 2,5 milhões de assinantes deletado em 2018, mas sob pretexto de discurso de ódio contra islâmicos e transgêneros e pelo upload de conteúdo violento ${ }^{20}$, não por desinformação. Contudo uma enorme quantidade de canais dedicados à teoria da conspiração e pseudociência continuam hospedados no YouTube, com muitos dos seus vídeos recebendo grande audiência e passando completamente despercebidos de qualquer interferência do site. Analisaremos a seguir um canal brasileiro dedicado a defender a teoria de que a Terra é plana.

\section{Professor Terra Plana}

Nosso artigo foca a análise no canal brasileiro Professor Terra Plana, que desde outubro de 2017 se dedica a postar conteúdo pseudocientífico que dá voz a argumentos terraplanistas no YouTube. Dada a ausência de pesquisa sistemática sobre esse universo, nossa análise tem um caráter exploratório, e se propõe a definir as características básicas do canal, identificar as relações que ele estabelece com agentes do seu entorno ideológico e, também com seus adversários, uso de recursos comunicativos e retórica. Como muitos outros espaços conspiracionistas hospedados no site, a autoria dos vídeos é de difícil identificação, manifestada através de pseudônimos e com ligações minimalistas a pessoas físicas. Na descrição dos vídeos do canal, links para outras páginas terraplanistas são listados, a maioria delas também anônimas; uma página do Facebook também é listada, dedicada em repostar conteúdo conspiracionista desta e de outras páginas; e a autoria do conteúdo é discretamente creditada ao editor Siddhartha Chaibub Lemos e ao narrador Hiram Motta Lima.

\footnotetext{
19 Manifestação do YouTube prometendo dar menos visibilidade para vídeos contendo teorias da conspiração. Disponível em: 〈https://bit.ly/2qmGNQp>. Acesso em: 30 set. 2019.

${ }^{20}$ Reportagem do The Verge de Agosto de 2018, quando o YouTube removeu o canal do conspiracionista Alex Jones do ar. Disponível em <https://bit.ly/2qlMj5H>. Acesso em: 30 set. 2019.
} 


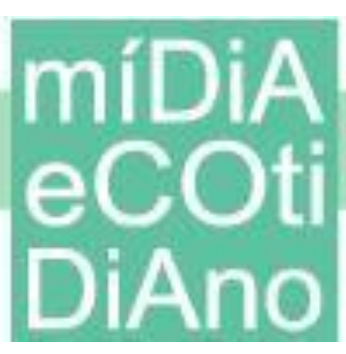

Com cerca de 27 mil inscritos, o canal conta com 1.548.291 de visualizações (números de setembro, 2019); seus vídeos mais visualizados chegam a ultrapassar 200 mil visualizações, variando entre três minutos e três horas de duração. Fazendo uso de uma edição de imagens guiada por uma narração - e, por vezes, contendo com animações criadas pelos autores - o canal expõe o que defende serem falácias no argumento científico de que a terra é plana, atacando instituições como a NASA, enaltecendo a Bíblia e contestando explicações consolidadas como sobre a rotação da terra, fusos horários, a Lua, satélites e a gravidade. Evocando o tradicional discurso de teorias da conspiração, o narrador aponta interesses de forças ocultas em esconder o verdadeiro formato do planeta; geralmente apontando judeus e maçons como integrantes destes grupos, globais e sob controle de grandes instituições.

Em nenhum momento do canal algum indivíduo aparece falando diretamente para câmera, com o conteúdo sendo exclusivamente narrado em voice-over, embora animações caracterizando o Professor Terra Plana ocasionalmente apareçam. Nenhuma menção a questões pessoais dos autores é mencionada - menções aos responsáveis pelo canal aparecem discretamente abaixo do vídeo. O canal não faz menções a movimentos políticos brasileiros ou estrangeiros, mesmo aqueles que recentemente manifestaram simpatia à ideia do terraplanismo, como Olavo de Carvalho ${ }^{21}$.

Uma análise mais detida, contudo, revela a inserção do canal numa rede mais ampla, que tem como nó o canal "A Terra é Plana - Flat Earth", apontado na descrição do Professor Terra Plana. Lá encontramos conteúdo similar ao do canal associado: enquanto não há vídeos exatamente iguais, o estilo de edição é parecido, com a mesma dupla recorrente por trás das produções. Ao contrário do foco em conteúdo original do Professor Terra Plana, este canal também realiza traduções de conteúdo estrangeiro sobre o tema, frequentemente creditando vídeos ao terraplanista americano Eric Dubay. "A Terra é Plana" também reconhece diretamente figuras brasileiras, enaltecendo

\footnotetext{
${ }^{21}$ Matéria do Último Segundo mostra comentários de Olavo de Carvalho sobre o terraplanismo: Disponível em: <https://bit.ly/2Lp5BOQ>. Acesso em: 29 set. 2019.
} 


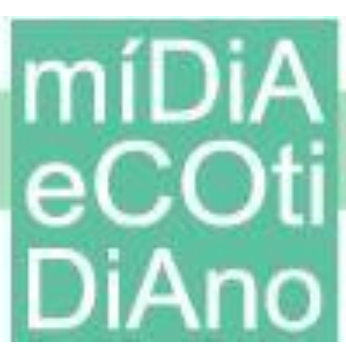

argumentos de Olavo de Carvalho e atacando a Rede Globo. O canal também publica vídeos sobre conspirações envolvendo o flúor na água, rastros químicos, dinossauros e paralisia do sono, além de anunciar o lançamento da Revista Terra Plana, à venda em um site dedicado pelo preço de 19 reais $^{22}$. Na descrição de um vídeo, o canal aponta 56 outros canais brasileiros dedicados ao tema.

Figura 1 - Parte da longa lista de canais terraplanistas brasileiros indicados pelo A Terra é Plana

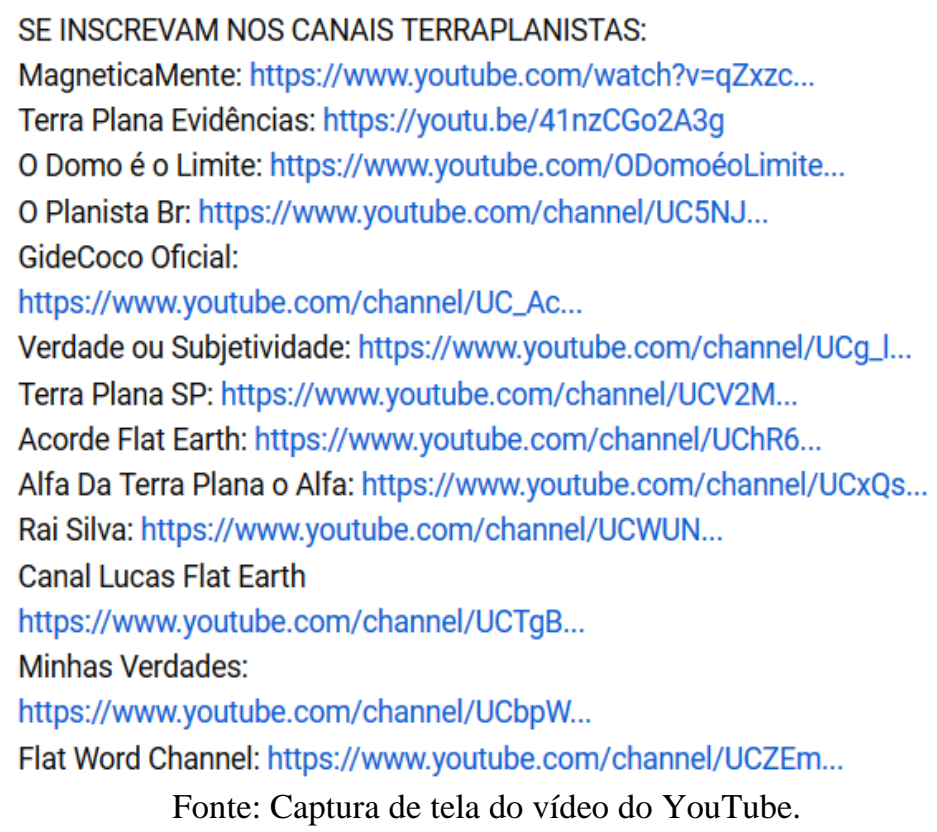

Há todo tipo de apresentação de conteúdo na rede terraplanista brasileira: vlogs, apresentados em primeira pessoa por autores que defendem passionalmente os argumentos; canais apenas dedicados a legendar conteúdo estrangeiro sobre a Terra Plana; produtores de narrativas como os dois canais que apresentamos anteriormente. Alguns são completamente anônimos, enquanto outros divulgam e se apresentam com nome e sobrenome ou discretamente informam nos créditos. O conteúdo é expandido por centenas de autores independentes para páginas do Instagram, Facebook e domínios

\footnotetext{
22 Revista terraplanista é vendida através do site. Disponível em: <http://www.revista.clubeterraplana.com.br/>. Acesso em: 29 set. 2019.
} 
próprios em sites dedicados; o Datafolha apontou em junho de 2019 que 11 milhões de brasileiros acreditam que a terra é plana ${ }^{23}$.

Os canais também não aparentam enfrentar qualquer tipo de interferência do YouTube. No ar há dois anos, o Professor Terra Plana permanece com seu catálogo de vídeos intacto, com publicações frequentes desde que foi ao ar. Apesar de a plataforma manifestar recentemente medidas de combate à desinformação ${ }^{24}$, nenhum conteúdo foi removido dos canais nos últimos meses; a exposição também não parece ter sido radicalmente afetada, com um vídeo recente alcançando a marca de 27 mil visualizações ${ }^{25}$. Não está disponível a situação de monetização do canal, portanto não é possível determinar se alguma mudança recente de política de financiamento afetou os autores.

O Professor Terra Plana constrói seus argumentos unificando antigas posições criacionistas com pseudociência e teorias da conspiração modernas, consolidadas em mídias sociais em período de crise epistemológica. Boa parte do seu conteúdo está alinhado com o discurso público de políticos de extrema-direita, reproduzindo um discurso anti-institucional e tentando seduzir suas audiências com a poderosa possibilidade de "abrir os olhos", encontrando uma verdade que não é sabida por grande parte da população.

23 Datafolha aponta que 11 milhões de brasileiros são terraplanistas. Disponível em: <https://bit.ly/2PcAZkY>. Acesso em: 29 set. 2019.

${ }^{24}$ Matéria do NY Times sobre mudança de política do YouTube sobre conteúdo conspiracionista. Disponível em: <https://nyti.ms/3654ImE>. Acesso em: 30 set. 2019.

${ }^{25}$ Vídeo do canal Professor Terra Plana sobre satélites. Disponível em: 〈https://bit.ly/2rZSeh6>. Acesso em: 30 set. 2019. 
Figura 2 - Descrição do Professor Terra Plana

Descrição

A terra está parada. Não se move.A superfície da Terra é plana. Há uma cúpula sobre nós chamada o Firmamento. 0 sol, a lua e as estrelas estão sob a cúpula do Firmamento. 0 sol e a lua são muito menores e mais próximos do que nos dizem. 0 sol e a lua se movem em seus próprios padrões sobre a superfície da Terra. Não há planetas. Apenas estrelas no céu. Não há espaço.Não podemos sair da cúpula.Não existe um universo interminável e caótico que se criou.Nós temos um criador e nós temos um propósito! : Quem tiver interesse em participar desse grupo favor mandar um e-mail para professorterraplana@gmail.com, Ou Pelo Inbox Pela nossa página no Facebook: https://www.facebook.com/aterraeplana/ Ou no Instagram:

https://www.instagram.com/aterraeplanaoficial/

GRUPO DA PÁGINA A TERRA É PLANA E DO CANAL PROFESSOR TERRA PLANA (APENAS PARA TERRAPLANISTAS CONVÍCTOS COM PERFIL NO FACE QUE LHE IDENDIFIQUE)

Fonte: Captura de tela do vídeo do YouTube.

Escolhemos para análise o vídeo “As 35 Perguntas Mais Frequentes Sobre A Terra Plana Respondidas"26, postado em 05 de julho de 2018, dono de 108 mil visualizações. Estruturado no formato de FAQ, a narrativa de 46 minutos ilustra a construção do pensamento terraplanista de forma precisa ao responder perguntas primárias sobre diferentes tópicos.

O vídeo nega diversas noções aceitas pelo senso comum como a gravidade, o tamanho do Sol, a existência de outros satélites, planetas e estrelas (estas, luzes no céu que se mexem enquanto a Terra está parada no centro do universo) e indica uma conspiração global que envolve instituições da ciência (referida pelo vídeo como "pseudociência" em todas suas menções), governamentais e da mídia. O autor argumenta que a Antártida é uma grande parede de gelo onde o mundo termina, por isso, o governo autoriza apenas um grupo seletos de pessoas para viajar até lá. Ele acusa a NASA de criar "com o photoshop" as imagens da terra vista no espaço, de chamar pedras comuns de meteoros, de lançar mísseis no céu para simular asteroides, e reproduz antigas teorias da conspiração de que o homem nunca pisou na lua, sendo tudo "mais uma grande farsa da NASA".

26 Vídeo do canal Professor Terra Plana analisado neste artigo. Disponível em: <https://www.youtube.com/watch?v=IkcDpotI4lQ>. Acesso em: 30 set. 2019. 


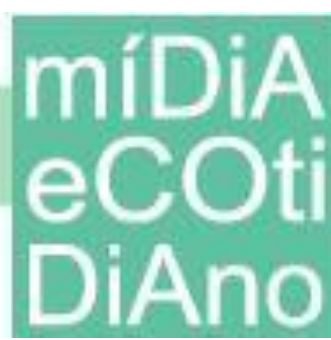

\section{PPGMC}

uff

Figura 3 - Edição do vídeo acusa vídeos da International Space Station de serem farsas produzidas em estúdio pela NASA

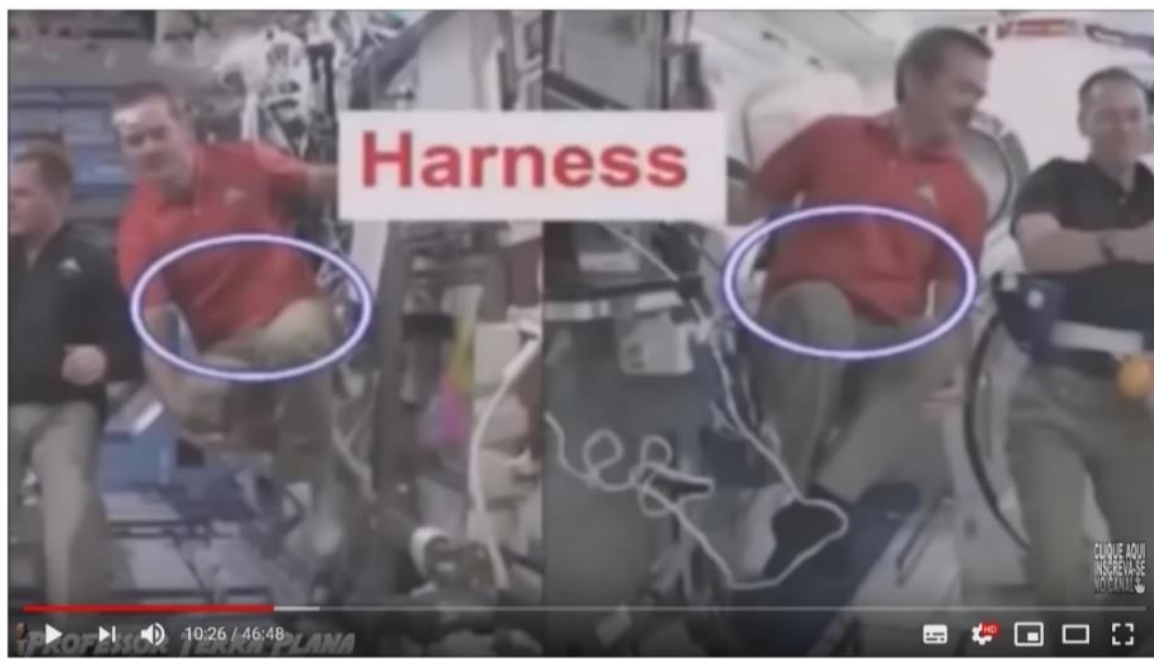

AS 35 PERGUNTAS FREQUENTES SOBRE A TERRA PLANA RESPONDIDAS

Fonte: Captura de tela do vídeo do YouTube.

Figura 4 - O formato do mundo, para o canal, é exemplificado pela bandeira da ONU

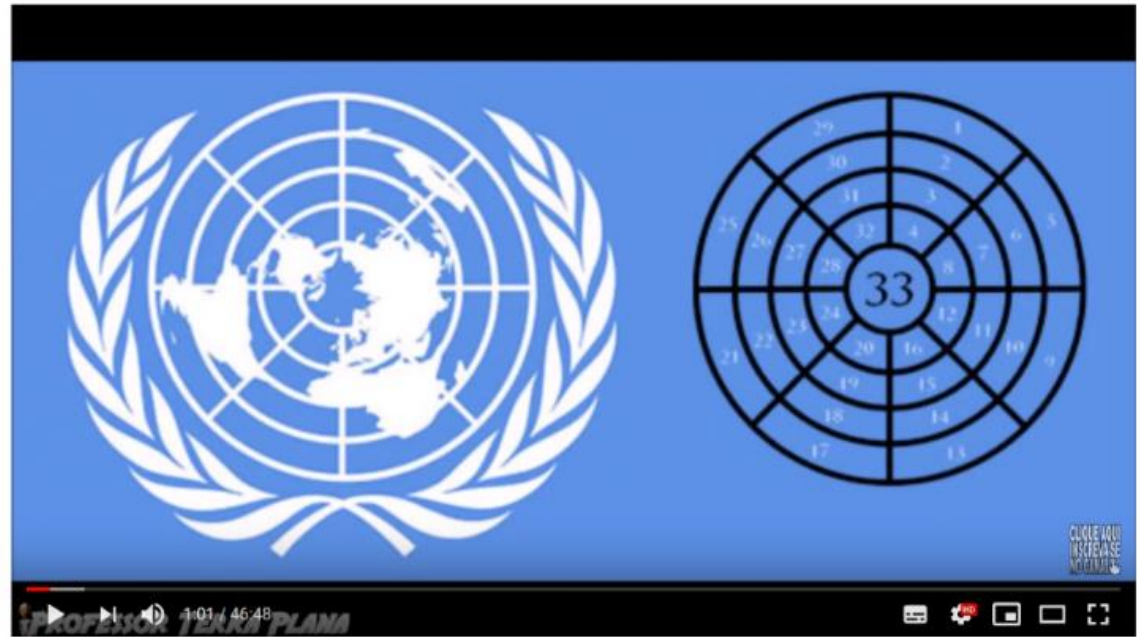

AS 35 PERGUNTAS FREQUENTES SOBRE A TERRA PLANA RESPONDIDAS

Fonte: Captura de tela do vídeo do YouTube.

A Bíblia é um objeto a ser reverenciado, embora não seja central em vários argumentos. Ela é apontada como "instituição científica, escrita antes do modelo eurocêntrico ser fantasiado, sem fazer menções a uma bola imaginária vagando loucamente no espaço". A NASA não é a única instituição a ser descredibilizada; a antiga associação terraplanista Flat Earth Society, fundada em 1956, é apontada como “oposição 
controlada" (evocando supostas palavras de Lenin), criada pela maçonaria para ridicularizar o movimento. Ele critica as crenças diferentes da fundação, que acredita que a terra é convexa, e não plana, e tem opiniões divergentes sobre a gravidade.

Em várias das perguntas, o canal ressoa diretamente teorias da conspiração que propõem a existência de uma nova ordem mundial, apontando diretamente grupos como Iluminatti, Globalistas, maçons e judeus como responsáveis pela corrupção do jornalismo e da ciência. Figuras como Newton, Galileu, Copérnico, Pitágoras e Foucault são apontadas igualmente como integrantes desta conspiração, que pretende estabelecer a partir de um pequeno grupo o controle de toda a humanidade:

A maçonaria é uma das maiores sociedades secretas do mundo, e uma das mais antigas que vai até possuir milhões de membros em todo o mundo. A NASA é cheia de maçons, dos quais executam suas tarefas, assim como a maioria das pseudociências eurocêntricas ao longo da história foram tramadas por maçons, como Newton, Galileu, Copérnico e até mesmo Pitágoras, do qual seria um dos primeiros maçons da ordem dos jesuítas. O vaticano hoje possui vários dos principais telescópios do mundo, incluindo um que eles chamam de L.U.C.I.F.E.R; os jesuítas também são conhecidos por estarem conectados a tudo isso. Essa elite possui controle de bancos, indústrias e corporações mesmo sendo a maçonaria, a sociedade secreta que vem empurrando este engano, e ela continua sendo o pilhar dos Iluminatti, que são compostos por 13 famílias que comandam e governam este mundo (PROFESSOR TERRA PLANA).

Investigações independentes, autores pseudocientíficos e Deus são as únicas fontes apontadas como confiáveis pelo autor, que propõe em sua obra um posicionamento anti-sistema, anti-epistemologico, apoiado na remoção da credibilidade de grupos que têm autoridade tradicional pelo saber, elaborando um novo tipo de pensamento conservador que une um antigo fundamentalismo às práticas modernas conspiracionistas desenvolvidas nas mídias digitais em tempos de crise epistemológica.

\section{Conclusão}

Teorias da conspiração ocupam um lugar de crescente importância no mundo contemporâneo. Por muito tempo, elas permaneceram um objeto pouco explorado pela pesquisa, talvez com base na crença de que o caráter exótico do conteúdo por elas 
propagado as desqualificava como objeto de pesquisa séria. Isso se comprovou um grande erro, contudo. A influência obtida por esse tipo de conteúdo fica evidente quando se considera que Olavo de Carvalho - o guru da família Bolsonaro - um ávido divulgador de conteúdo terraplanista ${ }^{27}$, conta com prestígio o bastante no governo para indicar os ministros da Educação Abraham Weintraub (que considera a palavra "Educação" carregada de sentido ideológico ${ }^{28}$ ) e das Relações Exteriores, Ernesto Araújo (que mais de uma vez participou de fóruns promovidos por grupos que negam o aquecimento global $\left.^{29}\right)$.

Teorias da Conspiração devem, portanto, ser levadas a sério. Elas são produto de um problema mais profundo: uma crise epistemológica que resulta da relação problemática dos indivíduos com as instituições modernas, que dá lugar ao crescimento da pseudociência e do extremismo religioso. Enquanto o enfraquecimento das instituições modernas merece atenção, novas tecnologias de comunicação também podem favorecer estes fenômenos. Para além da concepção tradicional da divulgação científica, que toma o status da Ciência como um dado, e apenas busca maneiras de fazer com que ela atinja o público leigo, é necessário enfrentar o desafio apresentado por discursos que desafiam a autoridade científica, como aquele que analisamos aqui.

\section{Referências}

AARTS, Kees; VAN DER KOLK, Henk. Understanding the Dutch "No": The Euro, the East, and the Elite. PS: political science \& politics, v. 39, n. 2, p. 243-246, 2006.

AUPERS, Stef. 'Trust no one': Modernization, paranoia and conspiracy culture. European Journal of Communication, v. 27, n. 1, p. 22-34, 2012.

AZARIAS, Wiverson. Não confie em ninguém-Teorias da Conspiração como Mitologia Política. Revista Alabastro, v. 2, n. 6, p. 45-51, 2015.

BAUDRILLARD, Jean. Simulacra and Simulations. Ann Arbor: Univesrity of Michigan Press, 2000.

BECK, Ulrich. Risk Society: Towads a New Modernity. London, Sage, 1992

\footnotetext{
${ }^{27}$ Olavo afirmou que não há nada que refute o terraplanismo. Disponível em: 〈https://bit.ly/2RkL9m4>. Acesso em: 12 nov. 2019.

28 Weintraub contestou a palavra "educação": "quem educa é a família". Disponível em: <https://bit.ly/2rSdK7N>. Acesso em: 12 nov. 2019.

${ }^{29} \mathrm{O}$ ministro mais uma vez questionou o aquecimento global. Disponível em: 〈https://bit.ly/2YhUeNW>. Acesso em: 12 nov. 2019.
} 
BOYD-BARRETT, Oliver. Fake news and 'RussiaGate'discourses: Propaganda in the posttruth era. Journalism, v. 20, n. 1, p. 87-91, 2019.

DAHLGREN, Peter. Media, knowledge and trust: The deepening epistemic crisis of democracy. Javnost-The Public, v. 25, n. 1-2, p. 20-27, 2018.

DOVEY, Jon. Freakshow: First Person Media and Factual Television. London: Pluto Press, 2000.

GARWOOD, Christine. Flat Earth: The History of an Infamous Idea. Macmillan, 2007.

GILLESPIE, Tarleton. The politics of 'platforms'. New media \& society, v. 12, n. 3, p. 347$364,2010$.

GIDDENS, Anthony. Modernity and Self-Identity: Self and Society in the Late Modern age. Stanford, CA: Stanford Univesity Press. 1992.

HABGOOD-COOTE, Joshua. Stop talking about fake news!. Inquiry, v. 62, n. 9-10, p. 1033 $1065,2019$.

KEELEY, Brian L. Of conspiracy theories. The Journal of Philosophy, v. 96, n. 3, p. 109-126, 1999.

KNIGHT, Peter. Conspiracy Culture: From Kennedy to the X-Files. London and New York: Routeledge. 2000.

LASCH, Christopher. The Culture of Narcisism. New York: WW Norton and Company, 1979.

MANHEIM, Karl. (1935). Man and Society in an Age of Reconstruction: Studies in Modern Social Structures. London: Kegan Paul, Trench, Trubner and Co. Ltd, 1946.

LILLEKER, Darren. Politics in a post-truth era. International Journal of Media \& Cultural Politics, v. 14, n. 3, p. 277-282, 2018.

NICOLAS, Loïc. As teorias da conspiração como espelho do século: entre a retórica, a sociologia e a história das ideias. Revista Eletrônica de Estudos Integrados em Discurso e Argumentação, n. 12, p. 255-279, 2016.

OLIVEIRA, Thaiane Moreira de. Autoridade Científica Em Tempos de Crise Epistêmica: a circulação de teorias da conspiração em redes sociais. In: Encontro Anual da Compós. 28., 2019, Porto Alegre-RS. Anais... Porto Alegre-RS: Pontifícia Universidade Católica do Rio Grande do Sul. 2019

PARKS, Lisa. Flexible Microcasting: Gender, generation and television-Internet convergence. In: SPIGEL, Lynn; OLSSON, Jan. (eds.). Television after TV: Essays on a Medium in Transition. Durham: Duke University Press, 2004. p. 133-156

SANTOS JUNIOR, Marcelo Alves dos. \#VaipraCuba: a gênese das redes de direita no Facebook. Curitiba: Appris, 2019.

SILVA, Sandra. Teorias da conspiração: Sedução e Resistência a partir da Literacia Midiática, 87 f. Dissertação (Mestrado em Ciências da Comunicação). Faculdade de Letras da Universidade de Porto, Porto, 2010.

SOUKUP, Charles. Television viewing as vicarious resistance: The X-Files and conspiracy discourse. Southern Journal of Communication, v. 68, n. 1, p. 14-26, 2002. 
TANDOC JR, Edson C.; LIM, Zheng Wei; LING, Richard. Defining "fake news" A typology of scholarly definitions. Digital journalism, v. 6, n. 2, p. 137-153, 2018.

VAN ZOONEN, Liesbet. I-Pistemology: Changing truth claims in popular and political culture. European Journal of Communication, v. 27, n. 1, p. 56-67, 2012.

VAN DJICK, José. The Culture Of Connectivity: A Critical History of Social Media. Oxford University Press, 2013.

WOOD, Max. Has the internet been good for conspiracy theorizing? PSYPAG Quaterly, Special Issue: The psychology of conspiracy theories, Issue 88 September 2013. 